Association for Information Systems

AIS Electronic Library (AISeL)

Internationalization of students' learning using online technology: Lessons learned

Thomas Mejtoft

Helen Cripps

Stefan Berglund

Jasmina Dlacic

Matia Torbarina

Follow this and additional works at: https://aisel.aisnet.org/bled2019

This material is brought to you by the BLED Proceedings at AIS Electronic Library (AISeL). It has been accepted for inclusion in BLED 2019 Proceedings by an authorized administrator of AIS Electronic Library (AISeL). For more information, please contact elibrary@aisnet.org. 


\title{
Internationalization of students' learning using online technology: Lessons learned
}

\author{
Thomas Mejtoft, Helen Cripps, Stefan Berglund, \\ JASMINA DLACIC \& MATIA TORBARINA
}

\begin{abstract}
The global nature of business has increased the importance of students' international experience during their studies at the university. Using interactive technologies the projects investigated ways to increase students' motivation to take responsibility for the learning process by creating "real" international co-creation experience online. This paper presents learnings from two consecutive international collaborative teaching between Edith Cowan University, Australia, and Umeå University, Sweden, in 2017 and Edith Cowan University and the University of Rijeka, Croatia, in 2018. Feedback from the students showed they enjoyed working across cultures and academic discipline on simulated products and marketing campaigns. Issues raised included: the need to explicitly explain how all parts of project is going to work and how the students execute their role. Incorporation of a formal introduction process for the students in each location so all students have the same knowledge about each other. Furthermore, the provision of real-time opportunities to collaborate in lectures and the setting joint deadlines between the units are of importance. Despite some of the shortcomings of the project, it has provided a firm foundation for the refinement of ongoing collaborative teaching.
\end{abstract}

Keywords: - Higher education - Online technologies - International collaboration $\bullet$ Learning experience $\bullet$ International $\bullet$

Correspondence AdDress: Thomas Mejtoft, PhD, Associate Professor, Umeå University, Department of Applied Physics and Electronics, Digital Media Lab, Umeå, Sweden, e-mail: thomas.mejtoft@umu.se. Helen Cripps, PhD, Senior Lecturer, Edith Cowan University, Business and Law, Perth, Australia, e-mail: h.cripps@ecu.edu.au. Stefan Berglund, Lecturer, Umeå University, Department of Applied Physics and Electronics, Digital Media Lab, Umeå, Sweden, email: stefan.berglund@umu.se. Jasmina Dlacic, PhD, Assisstant Professor, University of Rijeka, Faculty of Economcis and Business, Rijeka, Croatia, e-mail: jasmina.dlacic@efri.hr. Matia Torbarina, PhD Student, Teaching Assistant, University of Rijeka, Faculty of Economcis and Business, Rijeka, Croatia, e-mail: matia.torbarina@efri.hr. 


\section{$1 \quad$ Introduction}

The global nature of business has increased the importance of students' international experience during their studies at the university (Guillotin, 2018). Even though students, most often, have the option to study part of their education abroad, this is not possible for all students. However, the proliferation of interactive technologies now allows for international virtual collaboration. This paper gives insights and from a project with the aim to give students international experience without going on exchange studies. The projects were designed to investigate the possibility of increasing students' motivation to take responsibility for the learning process by creating "real" situations (DuHadway \& Dreyfus, 2017), in this case including international co-creation experience without having to travel abroad.

Over the past 5 years, there has been an increasing number of on online collaborative tools introduced into the business environment with a range of specialty functions such as file sharing, video conferencing, and communication. Products such as Slack; Yammer; Dropbox; Google drive; Skype and Zoom have become commonplace. There has also been a spill over from personal social media into the business realm with social platforms, such as WhatsApp, WeChat, Facebook Messenger, LinkedIn and Viber now becoming commonplace. The use of online virtual collaborative technology has become central to current business practices especially in Australia due to its physical isolation. While most students are familiar with the array of social media channels for personal interactions, they are less skilled in using online collaborative tools in a professional business setting. Online collaborative tools are now used in the workplace to interacting with colleagues; crowdsource ideas; create innovative marketing content; and engage potential customers (De-Marcos et al., 2016).

In order to improve students' skills a professional and international context the students participated in an international online collaboration through digital platforms to provide students with a globally relevant and transformative social learning experience (Cela, Sicilia, \& Sánchez, 2015). The project was devised to exposed students to the business practices of collaboration, co-creation and crowdsourcing to improve their career readiness. Involving students in an international collaboration was designed to increase students' exposure for different cultures and business practices by working with students from another 
country. It was also structured to improve students technical skills in the use of online collaborative tools in a business setting, which it was hoped, would develop their employability through the co-creation of a product and digital marketing content for an international audience. Furthermore, in one of the collaborative projects describes below, the students also were exposed to interdisciplinary collaboration.

\section{Collaborative Project 1: Umeå University - ECU collaboration}

A collaborative curriculum was developed combining a Marketing unit (Current Issues in Marketing) at Edith Cowan University (ECU) and an engineering unit (Prototyping for Mobile Applications) at Umeå University. The project incorporated a number of steps that interwove between the two units, with information being exchanged over the semester. As the semesters between the two Universities did not coincide, the ECU students commenced work on the project four weeks before the Umea students.

The challenge in the design of this collaborative curriculum was that the students must be able to finish their unit in case of collaborative problems. Hence, there was no total dependence between the two units and the lecturers used ad hoc flexibility over the course of the collaboration. It was also decided not to give the students all information about the project at the start of the units but rather on a need-to-know basis.

Collaboration process entailed the ECU students forming teams and created an online public blogs containing information drawn from academic and industry literature relating areas of marketing innovation such as smart home technology, connected devices, online media, gamification and environmental sustainability. The blog post formed part the ECU students' assessment for the unit. Then the students at Umeå University students reviewed the blog posts as part of their preliminary research for which they developed their Mobile apps. ECU and Umeå University students used Slack to exchange information and ideas about the app that are being prototyped by the Umeå University students. Umeå University students created a video about their proposed apps in English and posted it on Slack for the ECU students. Using information supplied by the Umeå University students the ECU students develop an informational marketing video around one of the app prototype they select from those present by the 
students from Umeå University in Sweden. These presentations form part of the Umeå University students' assessment and was marked by the teaching staff at Umeå University. The ECU students created marketing collateral including a product Facebook page, promotional video and linked back to their and a post on their blog announcing the launch the product. These marketing material formed part the ECU students' assessment for the unit and their processional portfolio.

\subsection{Assessment of the collaborative project}

The student review of the project showed that they liked the idea of the project but a more structured approach would be beneficial. Students on both sides of dyad often struggled with the unknowns, as they were reliant on students half a world away. However, from the communication platform it could be observed that the students exhibited skills in finding solutions and workarounds to complete their assessments.

Experiences and learnings from the project include:

1. The need to explicitly explain how all parts of project is going to work and how the students execute their role,

2. Supervise a formal introduction of the students in each location so all students have the same knowledge about each other,

3. Provide real-time opportunities by setting Swedish lectures in the morning and Australia lectures in the afternoon, and

4. Set joint deadlines between the two units and make clear the consequences of failing to meet deadlines.

Challenges during the collaborative project included, stilted exchanges on issues due to time differences, differing understandings of cultural priorities and aligning the timing of assessment of the units' requirements. However, benefits to the students included, experience to give and receive feedback, experiencing a new business culture and technologies, development of online media skills and having to solve real world problems. For the Australian students an added benefit was the visit to Perth of one of the Swedish teachers, which supplement their online experience. This may have contributed to a greater positivity toward the project reflected in their unit evaluation. 


\section{Collaborative Project 2: ECU-University of Rijeka Collaboration}

As part of the implementation of new marketing unit called Social Media Marketing at ECU in 2018, a collaborative teaching project was established with the University of Rijeka, Croatia, related to Faculty of Economics and Business and the course Business to Business Marketing.

To assist with the local and international collaboration the "Social Studio Digital Hub" Facebook page was established to facilitate information and cultural exchange. The ECU students wrote marketing blogs about the Kvarner Region of Croatia, in which the University of Rijeka is located. Some of the ECU students posted their blogs on the Social Studio Digital Hub Facebook page, where some ECU and University of Rijeka students have commented on the content of the blogs.

It was originally intended that the University of Rijeka students would also view and comment on the ECU students' posts on the Facebook page however once again the students required a an assessment to motivate them to comment on the ECU blogs. To facilitate feedback on the ECU blogs, the University of Rijeka students participated in a workshop where they reviewed over 50 ECU blogs. As part of the process the University of Rijeka students developed a rating system for marketing blogs, which they applied to the ECU blogs. Rating criteria focused on blog appearance, information provided and perceived effort authors put in creating content. The main feedback was related to the poor user design of the blogs and lack of detailed information on the blogs.

In their second assessment in the Social Media Marketing unit, the ECU students had to create a social media marketing plan for a company from the Kvarner region. As part of this assessment, the ECU students need to read and incorporate all relevant feedback from the University of Rijeka students. Through SalesForce, ECU students viewed the marketing analytics on their posts and improve their campaigns, thus having a 360-degree view of digital marketing. The marketing insights gained from SalesForce enabled the students to create a more targeted and measurable social media marketing plan for a company on which the students had selected. This online collaboration exposes the ECU students to feedback from peers half a world away. It also designed to illustrate 
the complexity of online and international interactions, which are part of the globalized economy in which our students will work.

The outcomes of this project include providing students with the opportunity to develop digital marketing skills that will make them more competitive in the industry as they graduate. Additionally, the online collaboration exposed the ECU students to feedback from peers from another country and illustrates the complexity of online and international interactions that are part of the globalized economy. Most of the ECU students were very engaged in the project and enjoyed having feedback form peers form another country and the opportunity to take on the persona of a travel blogger. However, some of the ECU students questioned why they had to focus on an international location rather than a domestic market.

\subsection{Assessment of the collaborative project}

The University of Rijeka students evaluate their collaborative experience as moderately satisfied. But they are willing to participate in similar collaborative project again due to exposure to different cultures, communicating with students from another university as well as this activity was for them fun and refreshing in their curriculum. This activity was rated as interesting and exchange of information between different countries as well as because of being exposed to innovative way of teaching. They pointed out "the university should always come up with new projects and make things different than usual".

Benefits from this collaborative project from the students' perspective include internationalizing their learning experience, improving their English language skills, being involved in new way of teaching, communicating with other students and teamwork. They also pointed out that "it was cool to see that your student get tasks that are really based on practical work and not just theoretical". One student pointed out as positive that at the end they got the chance to meet one of the professors from ECU.

Most of the University of students did not perceived this collaboration to be frustrating. But some students pointed out "language barriers" that made him/her slightly frustrated about collaborative project. Still, they proposed some interesting improvements like video calls, more feedback, interpersonal 
communication between students or making it more complex task with aim to learn more. Some, elements that they suggested were planned but due to time zone difference they were demanding to actually implement them. Video reflection from an ECU professor was included in class lectures but one students pointed out that video should have been of higher quality and that sound was not quite understandable. All students pointed out that task was clear, understandable and could really evaluate effort that ECU students invested in creating Kvarner region blogs.

Experience and learnings from the collaborative project include:

1. Activity is perceived as interesting, fun and new perspective in teaching

2. Innovative approaches that include new ways of teaching and/or international collaboration are welcomed

3. More feedback is needed and students would appreciate more contacts with ECU students either video communication or through more extensive collaboration with ECU students

4. Have to think how to solve time difference to have more personal communication between students in classes.

Outcomes from this collaborative project included students' benefits like more international exposure, more exposure to different culture and improved language skills. Criteria they developed to evaluate blogs helped them to consistently evaluate more than 50 different blogs about Kvarner region that ECU students wrote. At the end students were satisfied with this project and would participate again in a similar project with more real-time collaboration between the students.

\section{$4 \quad$ Conclusion}

Analyzing the project among teachers involved, revealed some challenges, however all teachers consider that this type of international collaborative curriculum can benefit the students (cf. Chang \& Lee, 2013). Challenges during the collaborative project included, stilted exchanges on issues due to time differences, differing understandings of cultural priorities and aligning the timing of assessment of the units' requirements. However, benefits to the students included, experience to give and receive feedback, experiencing a new business 
culture and technologies, development of online media skills and having to solve real world problems. To further strengthen the collaboration between the teachers in the collaborative project between Umeå University and ECU, a faceto-face meeting and collaboration was also arranged in Perth in addition to the virtual collaboration (cf. Lin, Hu, Hu \& Liu, 2016). This was also an added benefit for the Australian students since the last feedback could be given on site. This may have contributed to a greater positivity toward the project reflected in their unit evaluation. For the students from University of Rijeka, a visit from one of the ECU teachers was perceived as added benefit.

Universities that focus on collaboration (Srikanthan \& Dalrymple, 2002) and internationalization, solving real-life problems like case studies (Damnjanovic \& Novcic, 2011) is positively influencing perceived quality from student perspective. This could influence not just future enrolment of students but also perception of the University's quality among other stakeholders, such as the industry. Hence, implementing collaborative real-life projects in teaching process influences not just students' curriculum but also marketing environment as well and consequently helps universities to acquire a better position in the educational landscape.

This project is ongoing and during spring 2019, the Umeå University-ECU collaboration will have a second try with another collaboration between an engineering unit in Sweden and a marketing unit in Australia. The overall aim during this project is further refine the process and find better touch points between the students that provides both short-term value (perceived by the students within the timespan of the unit) and long-term value (perceived by the students in their future profession) for the two different student groups. Also, for assessing collaboration project in future the same evaluation criteria will be applied in Australia, Sweden and Croatia.

\section{References}

Cela, K., Sicilia, M., \& Sánchez, S. (2015). Social network analysis in e-learning environments: A preliminary systematic review. Educational Psychology Review, 27(1), 219-246.

Chang, W., \& Lee, C. (2013). Virtual team e-leadership: The effects of leadership style and conflict management mode on the online learning performance of students 
in a business-planning course. British Journal of Educational Technology, 44(6), 986-999.

Damnjanovic, V., \& Novcic, B. (2011). Bringing the real world into your classroom applying the case study method( $\mathrm{mm})$. Changes in Social and Business Environment, 4, 27-32.

De-Marcos, L., García-López, E., García-Cabot, A., Medina-Merodio, J., Domínguez, A., Martínez-Herráiz, J., \& Diez-Folledo, T. (2016). Social network analysis of a gamified e-learning course: Small-world phenomenon and network metrics as predictors of academic performance. Computers in Human Behavior, 60, 312321.

DuHadway, S., \& Dreyfus, D. (2017). A simulation for managing complexity in sales and operations planning decisions. Decision Sciences Journal of Innovative Education, 15(4), 330-348.

Guillotin, B. (2018). Strategic internationalization through curriculum innovations and stakeholder engagement. Journal of International Education in Business, 11(1), 2 26.

Lin, X., Hu, X., Hu, Q., \& Liu, Z. (2016). A social network analysis of teaching and research collaboration in a teachers' virtual learning community. British Journal of Educational Technology, 47(2), 302-319.

Srikanthan, G., \& Dalrymple, J. F. (2002). Developing a holistic model for quality in higher education. Quality in Higher Education, 8(3), 215-224. 